\title{
CAUSATIVE FACTORS OF SOCIAL INEQUALITY AND ITS IMPACT ON COMMUNITY HEALTH: A NEIGHBOURHOOD LEVEL STUDY IN MIDNAPORE MUNICIPAL AREA, WEST BENGAL, INDIA
}

\author{
U. Roy \\ Department of Geography \\ University of Calcutta, Kolkata, W.B, India \\ utpalgeovu@gmail.com
}

Commission, WG VIII/2

\begin{abstract}
KEYWORDS: Causative factors, principal component analysis, social exclusion, neighbourhood, urban penalty and health
\end{abstract} disparity.

\begin{abstract}
:
Health is socio-demographic construct of population. In an urban area social, economic and political systems simultaneously operate within a geographically defined space in which the urban dwellers accommodate and act as key player. As such the physical and social factors virtually affect the community health as a consequence of disparity in accessing health. Health disparities in smaller towns of the developing world have drawn serious attention as they are poorly suffering from the problems of 'urban penalty'. This paper deals with statistical clustering of neighbourhoods on the basis of quality of life, social deprivation and multiple suffering quantified as the variables derived from measurable parameters. Neighbourhoods inequality has been mapped as per the score received by each neighbourhood in respect to the above three variables. Principal Component Analysis (PCA) has also been employed for grouping the neighbourhoods in social terms. Then it has been tried to examine relationship between health attainment and social status of the neighbourhoods. The study shows that status of health does not merely depend on socio-demographic and political factors but availability of healthcare facilities, health related behaviour, health perception and awareness have played significant roles. The findings of the study may be helpful for setting planning strategies most important of which would be inclusion of local people in catering health services.
\end{abstract}

\section{INTRODUCTION}

In the all sphere of human life, health is one of the most important factors for improving the functional system and attaining the higher standard of living in society. Health is a socio-demographic construct of a population. Health has been defined from various perspectives. As per WHO health as a "state of complete physical, mental and social well-being and not merely absence of disease and infirmity." The most important factors that govern health are poverty, welfare, development, individual health behaviour, gender, economy, ethnicity, psychological, environment etc. criteria of an urban community or an individual that play determining roles in achieving health and creating health inequalities. Parameters are chosen to define the above mentioned factors and to explain their pattern of distribution over space. These factors have been quantified by measurable parameters and their status in each neighbourhoods across the study area. Analysis of these factors at the neighbourhood level leads to identification of socially and economically disadvantaged neighbourhoods. In general an individual or a social group occupies a particular place within a particular space time framework which is characterized by the social context in which they live but any two person or two groups can not share the same space at the same time. The particular position in the spatio-temporal framework determines action and perception of the health actors. Therefore there is a close link between the health agent's behaviour and the social context in which it exists. On the contrary the social context is the manifestation of prevailing social structure designed by the social institutions and social processes operative. In this context, social hegemony, deprivation, subordination, concentration of power, social inability etc. are the processes that construct the nature of social structure of a place.

Differences in the degree of operation of these processes results in disparities in the landscape of health. Mainly multivariate statistical techniques have been applied to measure the variation in health status among the dwelling of each neighbourhood. Finally GIS platform supports the way in preparing the meaningful maps for visualization the degree of disparity.

\subsection{Introducing Study Area-Midnapore Municipal Area;}

The present study has been carried out over the Midnapore town that is an oldest urban centre and village town of West Bengal, India. Now it is the district headquarter of Paschim Medinipur district. This small town has a long glorious urban history since time immemorial. Apart from being a cultural citadel of the undivided Medinipur district, this small town has gained a wide reputation as an old seat of power. It is well known that based on the geo-political and commercial factors, this town was selected for district headquarters by the British Government. Midnapore is an age-old town that achieved urban status on $22^{\text {nd }}$ September, 1783 and since then it became the administrative head quarter of the district and thus serving as the single most important urban centre of a vast hinterland having a poor level of development. Midnapore is one of the oldest municipalities (estd. on $1^{\text {st }}$ April, 1865) of West Bengal. The urban development of Midnapore has undergone extensive metamorphosis of its socio-economic and demographic structure under the changing influences of historical, social, economic, political and administrative and many other determinants at local and regional scales. Such dynamism has been reflected on the 
morphological, occupational, livelihood, cultural and other behaviour of the urban system. Midnapore town is located on the left bank of Kansai River where $87^{\circ} 19^{\prime} \mathrm{E}$ meridian of longitude and $22^{\circ} 25^{\prime} \mathrm{N}$ parallel of latitude cross each other.

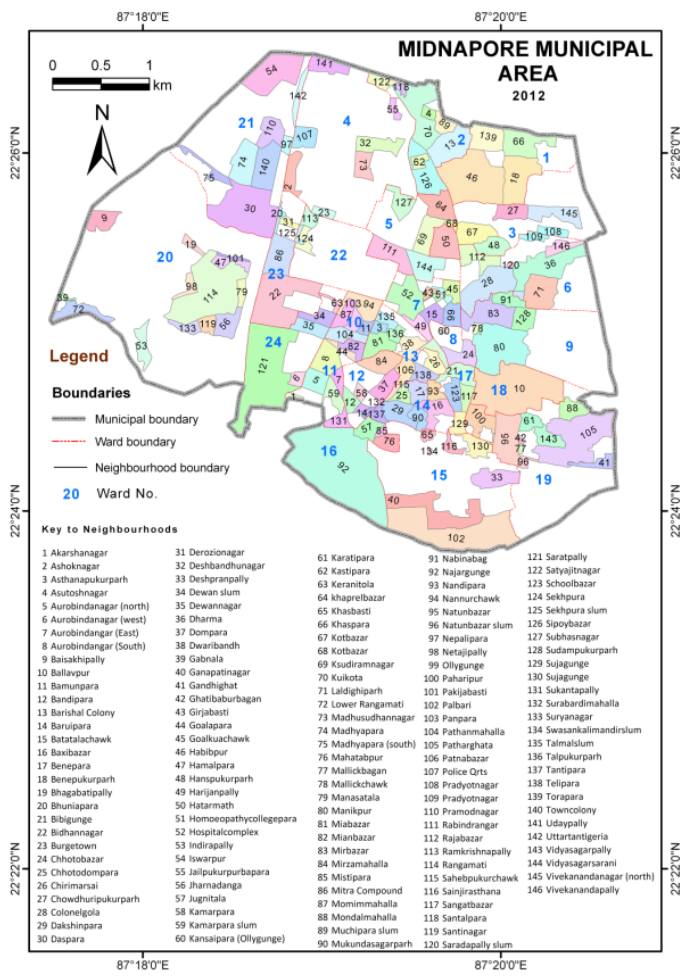

Figure 1. Location map of Study area with Neighbourhood Units

\section{CAUSATIVE FACTORS OF SOCIAL INEQUALITY}

Causative factors are the leading components in creating the social inequality. An urban area represents a geographically defined space where social, economic and political systems simultaneously operate in which the urban dwellers accommodate and act as key players. As such the physical and social health factors virtually affect the community health and designed by the urban community in a reciprocal manner. As a consequence of this process disparity in accessing health and health status develops giving rise to a landscape of power in which different socially defined groups play differently. Researches (Williams, 1990; Wolch and Dear, 1993; Hanchette, 1998; Last, 2001; Akhtar, Rais $2002^{4}$ ) have been carried out to establish the relationship between social status of urban communities and health considering social parameters as the determinants of the health. But in such works position of the social groups in the urban social hierarchy and their limitations in exercising their power in the social landscape have been less emphasized. In the changing socio-economic perspectives of third world village urban centres health perception, health behaviour, psychological stress (Barry and Yuill, 2002 ${ }^{7}$ ) etc. are emerging as significant issues of research interest which cannot be explained by traditional social determinants of health. Hence it is important to analyze the pattern of power structure within the urban framework so that the real situation of inequalities in the ability of accessing good health can be truly explained. Characterization of cohorts in demographic social and economic terms is an important task for assessment of health vulnerabilities. The following section deals in defining selected variables and identification of socio-economic and demographic groups within the study area which have higher susceptibility to become exposed to health hazards.

Although the coverage area of Midnapore Municipal Area is about $14 \mathrm{sq} \mathrm{Km}$ but the degree of heterogeneity among the NHs is prominent from central business district to periphery in almost all direction. Specially, central place of it occupied by old structure, traditional households. Most of the peripheral NHs have been developed during the first decade of $21^{\text {st }}$ century. Prolonged political turmoil, Maoist movement, reducing gainful return from agriculture, reduction opportunity in traditional occupation around the surrounding areas compelled the people to move from those area to Midnapore town. Irrespective of caste, religion, income group people participate in rural to urban migration. All these circumstances lead to become the important urban centre at Midnapore and which would create the huge diversity in terms of social, demographic, economic and health profiles. Finally diversity in various attributes have reshaped the geographies of the urban area. The sociogeographical contexts contribute to processes that create differences among the socially defined groups in terms of their empowerment to access health. Inequality in physical health between more and less fortunate social groups is the manifestation of interactions between percept, choice and behaviour of individual players within the social matrix that holds them. Health disparities in smaller towns of the developing world have drawn serious attention as they are poorly suffering from the problems of 'urban penalty' where management of healthcare system has become the most sensitive issue. Socially excluded and marginalized groups are found to share those spaces in the landscape of power and social sufferings which are exposed to the health related risks. Characterization of such spaces with higher degree of health vulnerability is necessary at the smallest possible level for health planning.

Inequalities in status of health, healthcare and health associated variables in different neighbourhoods of Midnapore Municipality are prominent. Some factors directly and others indirectly influence the health status and which generally make health disparities over the neighbourhoods. Inequalities among the neighbourhood in urban area reveal high degree of imbalances within the groups. Urban area is such place of rich people, as well as place of homelessness, place of aspiration, wealth on the other hand place of poverty. So this place reflects the wide magnitude of disparity between groups. Different groups of people co-exist in the urban area. so measures of heterogeneity concerning health and healthcare, socioeconomic condition are important task in urban studies. To find out the disparities over the urban area, neighbourhoods are taken as the unit of study. Because neighbourhoods exhibits considerable homogeneity with respect to health related attributes, socio-economic and demographic variables. Most of the people belonging to a particular neighbourhood, occupy more or less similar positions along the various gradients of urban life. But the population size of such a clan is large enough to allow statistical analysis without any technical problems. Moreover, neighbourhoods are relatively stable geographical areas having recognizable boundaries that do not change frequently. These are the advantages of adopting analysis of socio-economic and 
health inequalities at neighbourhood level. Information on socio-economic, health and demographic attributes were collected from door to door survey in each of the neighbourhoods using stratified samplings techniques. Questionnaire was prepared encompassing all selected variables. Thus more than 900 households were surveyed. All such data were aggregated or averaged at the neighbourhoods level to obtain an average value of each variable for each of the neighbourhoods. Socio-economic, health diversity within a small town is not rich enough that can be demonstrated easily. Therefore care had been taken to include health and health affecting variables as possible as so that differentiations between neighbourhoods can be displayed. 19 variables were taken to measure the disparity. These are associated with health, healthcare, demography, educational achievement, level of income, unemployment, and basic civic amenities.

\subsection{Measuring social inequality among neigbourhoods;}

All these selected variables were chosen carefully so that inequality $\mathrm{n}$ all aspect could be visualized rationally. In order to find out the significant result, different statistical analyses have been selected to measure the degree of inequality. These are- Correlation Analysis, Principal Component Analysis and Cluster Analysis (Bailey and Gatrell, $1995^{8}$ )were carried out in SPSS. Before employing analyses, all the data for each variable were standardized to mean $=0$ and variance $=1$. This was necessary to avoid the effects of differing scales of measurements (e.g Rupees, Years, Percentage) and also to avert unwanted dominance variables with higher variations in the results of statistical operation. Correlation analyses were performed for each pair of the selected variable. The correlations between pair of variables did not diverse grossly from expected trends. Such as, neighbourhoods having high income per member had been found to be characterized by higher calorie consumption $(\mathrm{r}=0.849)$, higher educated male $(\mathrm{r}=0.771)$, neighbourhoods having higher percentage of population engaged in higher professional activities ( $r=-0.710)$. The neighbourhoods where percentage of earning member associated with higher income occupation had been positively correlated to percentage of households having safe drinking water $(\mathrm{r}=0.683)$, having good environmental condition $(\mathrm{r}=0.610)$ and negatively correlated with percentage of population less than 15 years of age ( $r=-.813)$. The neighbourhoods with large family size having less $\%$ of higher educate adult male and female $(\mathrm{r}=-.334)$ and $(\mathrm{r}=-.230)$. It had also been found that neighbourhoods with higher percentage of BPL those having less proportion of people engaged in higher profession sector $(\mathrm{r}=-.448)$ and having higher percentage of children $(\mathrm{r}=0.59)$. Income of the family is negatively correlated with marriage age of women less than tender age ( $<18$ Years) $(r=-.343)$.

Another important and significant statistical analysis is Principal Component Analysis (PCA). It is a techniques used for multivariate analysis. Four principal components have been extracted. The First Principal Component (PC1) having eigen value 5.944 is the most important since 10 variables among 19 selected variables, have high loading on this component. PC1 accounts for the highest variance (31.286 $\%)$ in the data. Households are defined by electricity, separate kitchen, good household environment, higher calorie consumption by the family members, safe toilet, above poverty level, lower proportion of younger members, concretized roof, using LPG and relative higher engaged in government sectors. This PC1 reflects mainly social status of the household a neighbourhood.

Neighbourhoods with higher PC1 score represents those neighbourhoods which are socially advanced, conscious about health issue, most privileged class, demographically and environmentally sound with access to the basic amenities. A map has been prepared on the basis of score of

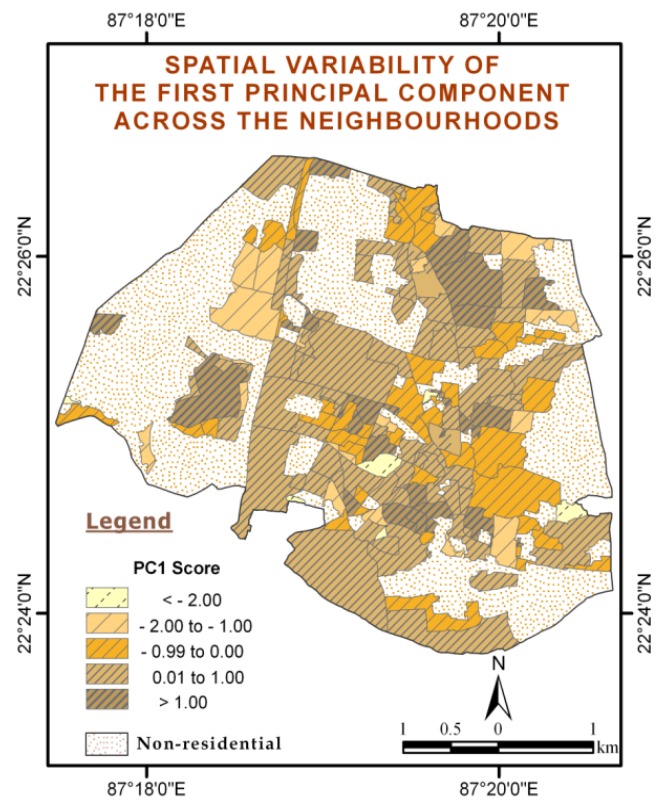

Figure 2. First Principal Component and NHs

PC1 to identify the spatial variability of neighbourhoods across the urban area. Some slum neighbourhoods belong to the very high of PC1 score these neighbourhoods are Bidhannagar, Mitracompound, Saratpally etc. All these neighbourhoods can be described as middle upper class neighbourhoods. The range of $\mathrm{PC} 1$ value varies from $<-.200$ to $>1$. All NHs over this area fall in between the range.

The Second Principal Component (PC2) explains the highest variance $(20.829 \%)$ PC1 and PC2 together explain $52.115 \%$ of the total variation in the data. PC2 is a component that includes 6 variables like male and female higher education, access to secure and safe water and relatively higher income and lower unemployment. All these conditions are really sound under some neighbourhoods with high PC2 value.

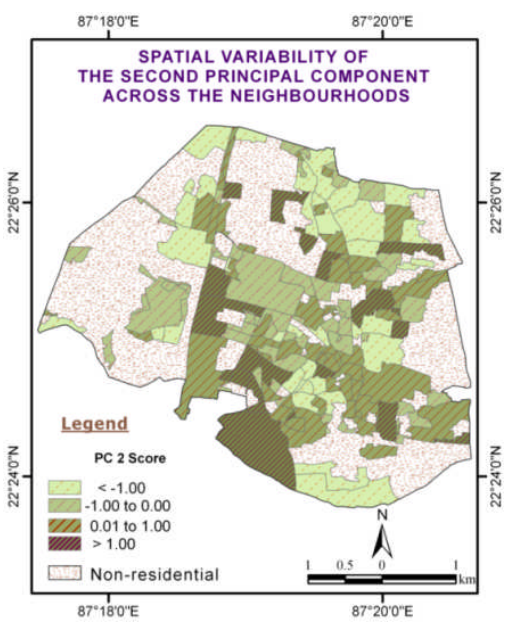

Figure 3. Second Principal Component with NHs 


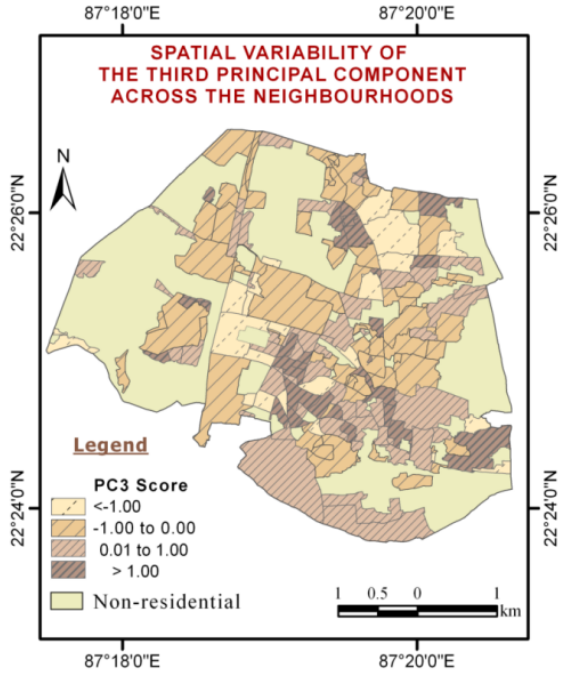

Figure 4. Third Principal Component and NHs

Most important aspects like social, economic and education status are indicated by PC2. PC2 score is higher in these neighbourhoods like Najargunge, Saratpally, Vivekanandanagar (north) etc. Because in middle income neighbourhoods, size of family is small that lowers the unemployment rate. Households under PC2 are more conscious about hygienic condition of environment because maximum households show high positive loadings on piped water connection $(+0.810)$, water purification $(+0.797)$. A map was prepared to exhibit the spatial variability of the Second Principal Component across the neighbourhoods.

The Third Principal Component (PC3) is mainly associated with two variables; this includes family size and living space of houses. The component loadings of these two variables are high on PC3. The neighbourhoods with higher score of PC3 (Fig-3.24) virtually represent those neighbourhoods where family members per household are high but living space is insufficient. In spite of that all members live together in an inadequate living space. These neighbourhoods are Surja Nagar, Bamunpara, Goalapara, Michipara etc. The poor neighbourhoods are characterized by higher percentage of owner occupancy because economically marginalized family used to dwell in poorly structured, congested, unhygienic houses and their limited capacity to purchase land compels them to live in a joint family. On the contrary, the neighbourhoods with low and medium low score of PC3 having 4 to 5 family members and neighbourhoods are attributed to good and healthy environment, room and man density is quite rational.

The Fourth Principal Component (PC4) is associated with marriage status of women of the household. This component loadings only one variable is high on PC4. This single variable is $\%$ of women get married in tender age $(<18$ years). Early marriage is such a type of social phenomena in the study area that does not depend on economic and educational status of the households. The PC4 score is high to those neighbourhoods like Aurobindanagar (north), Gandhighat, torapara etc. It also takes into account those neighbourhoods where parents of concerned households are really much more aware of the harmful consequences of early marriage to their daughters. One map of spatial variability of neighbourhoods has been prepared taking the score of PC4 over the study area. So this Principal Component is highlighting the demographic (women general health related) aspect of neighbourhoods. For organizing the all neighbourhoods into distinct groups, Cluster Analysis was performed. Neighbourhoods, these are belong to the same cluster exhibit high degree of homogeneity in some context like health, healthcare, socio-economic and demographic phenomena. The process of clustering was tried with increasing number of cluster using options available in the software to decide optimum number of clusters. It was continued until newly introduced clusters fails to include

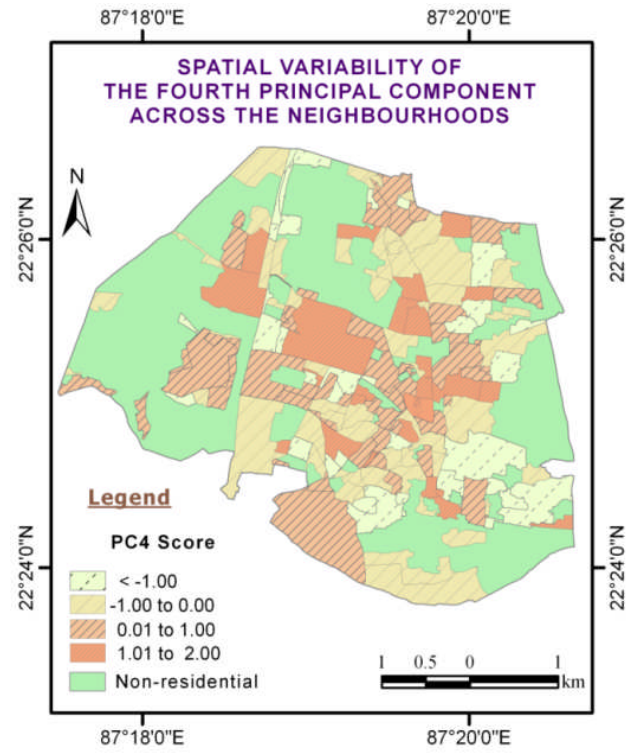

Figure 5. Fourth Principal Component and NHs

considerable number of neighbourhoods. Thus, four clusters determined, were found to provide the optimal splitting of the neighbourhoods into the cluster. The neighbourhoods belong to the same cluster exhibit large scale similarities in status of health profile and social well-being. The resultant clustering provides useful insight into understanding the basic problems of the neighbourhood types.

\section{DEGREE OF VARIATION IN COMMUNITY HEALTH}

In present study, we tried to find out the inequality in terms of quality of life, multiple suffering and social deprivation. These three analyses are being discussed below-

\subsection{Quality of life;}

Quality of life profile is developed to provide a measure that considers both the components and determinants of health and well-being. The profile emphasizes individual's physical, psychological, and spiritual functioning, and their connections with their environments and opportunities for maintaining and enhancing skill (Meade and Earickson, $2000^{20}$ ). So it has physical, social, economic and psychological dimensions. A map of quality of life has been produced for the study area using selected variables likes percentage of households having katcha roof, \% of households not having 24 hours access to safe drinking water, $\%$ of households not having separate kitchen, $\%$ of households not having pump facility, $\%$ of households withiout toilet within house, $\%$ of houlsehold not having water purification system. Statistical analysis of the database on the above social and economic indicators successfully helps to identify the high or low QOL in the neighbourhoods. 
Those selected socio-economic variables emphasize on the availability of basic urban amenities necessary maintaining good health status. Bidhannagar, Mitracompound, Rabindranagar, Keranitola neighbourhoods are identified as areas with high quality of life Synthesized indices related to household environment, income, occupation and educational attainment have been clubbed to derive the quality of life index for each neighbourhood which has been adopted as the basis for categorizing the neighbourhoods in a socioeconomic hierarchy. As such, the entire range of socioeconomic dimensions has been accommodated in the exercise of neighbourhoods stratification. In some NHs where level of quality of life is below the minimum standard namely Lower Rangamati, Khaspara, Kabordanga etc.

\subsection{Multiple Suffering;}

Many neighbourhoods across the Midnapore Municipality are suffering from number of problems. Some neighbourhoods are suffering from more than one social, economic problem, which have identified on the basis of calculation carried out by setting upper and lower limits of these selected variables. These variables are $\%$ of households having no electricity, $\%$ of household suffering from health care support, \% of household with low income per month etc. On the basis of degree of suffering all neighbourhoods have been grouped into two types and a map (Fig-7) as been prepared to present this account spatially. Of total, 22 neighborhoods do not have significant problems concerning income, access to safe toilet and electricity. On the other hand, remaining neighbourhoods are experienced by all these problems. Neighbourhoods suffering from more than one

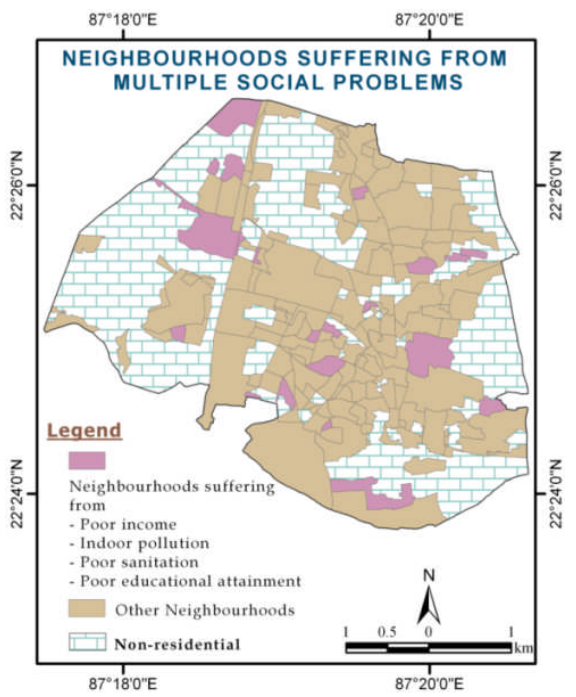

Figure 6. Neighbourhood with multiple suffering

social problem have been identified on the basis of calculations carried out by setting upper and lower limits of these selected variables. Most of the slum neighbourhoods and low income group neighbourhoods are having various types of problem. Few neighbourhoods located in terminal area of this municipality still do not have electricity connection to the all households like Gabnala, Indrani Pally, Lower Tantigaria etc. Monthly income less than Rs.1000.00 per family has been identified (as in 2009) for around 10 neighbourhoods (say, Karatipara, Mondal Mohallah, Natun Basti, Mgabnala et.) in the study area. All adult earning members of some households in Sekhpura Slum, Bamun Para, Natun Basti, are engaged with low professional activities. Still some inhabitants of some neighbourhoods used open ground as toilet. About $10 \%$ neighbourhoods do not have their own toilet facility but they are living under the Municipality area.

\subsection{Social Deprivation;}

An index of social deprivation has been derived incorporating several indicators like percentage of male unemployment, poor accessibility to healthcare facility, degree of overcrowding etc. thus the all neighbourhoods are categorized into four different zones considering the degree of social deprivation and finally one map of the same has been prepared for the Midnapore Municipality, Which basically helps to identify the disparities among the neighbourhoods in various concerns of social profile. This

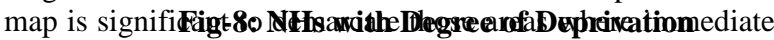
health, occupational support and infrastructural development

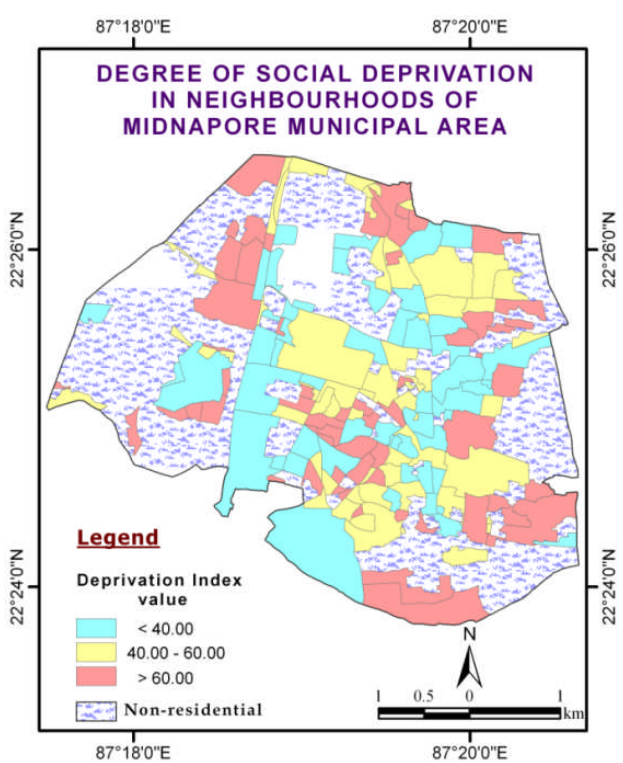

Figure 7. Neighbourhoods with degree of social deprivation

are required. Some neighbourhoods in the study area like Kamarpara Slum, Natun Basti Pakija Basti are having high social deprivation. In terms of magnitude of deprivation, these neighbourhoods attain a deprivation index value of 70 , which requires immediate health and occupational support and infrastructural development.

This analysis reveals that poor and slum neighbourhoods belong to the more deprived category and their location is far away from the main urban centre. Deprivation rate is moderate 50-70 in the total range. Some neighbourhoods fall in this category namely Asutoshnagar, Ballavpur, Tantigaria, Keranitola so on. Considering the attributes to measure social deprivation these neighbourhoods comes are under moderately low to low category of deprivation. Finally, Bidhan nagar, Ballavpur, colonelgola, Rabindranagar experience less deprivation because inhabitants of these neighbourhoods are mostly service holders in formal sectors and are privileged section in the urban area with index value less than 50. So this urban area is composed of number of socially heterogeneous social neighbourhoods.

Finally considering the value of quality of life, degree of social suffering and multiple suffering of each NHs, a map (Fig-9) of different social tiers has been made to visualize actural scenario of NHs together. A table-2 below shows the 
condition of some NHs with obtained value to each index and on the basis of this analysis all NHs ultimately categorized into four social tiers-poorer, poor, lower middle and upper middle.

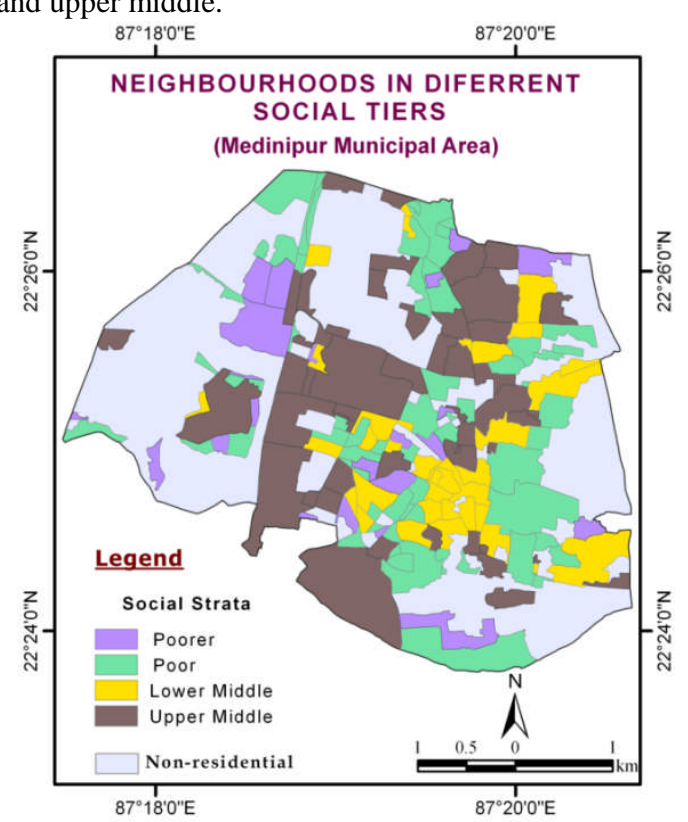

Figure 8. Status of neighbourhoods

\section{CONCLUSION}

This present work virtually aims at the determination of role of an area in influencing health. Area of residence presents an environment to which one individual is exposed. Health can be conceived as the manifestation of the intricate relationship between environment and people at various geographical scales like community, house and individual. Health environment has its physical as well as social, demographic, economic and political dimensions variation in health outcomes is a function of variation in the environment with which people interact. Health risk factors also vary between the places of residence depending on the environmental status. A considerable portion of this research work has been devoted to characterization of residential areas and people living in delineated neighbourhoods of Midnapore urban area. Similarly characterization of human groups at neighbourhoods level has also been carried out in relation to their socio-economic, demographic and health perspectives. Multivariate analyses have been employed to assess the contribution of deprivation and affluence on health outcomes. Local social and physical environment influence the health behaviour and health perception of an individual. Socio-spatial distribution of general amenities and resources are also very influential in determining health and ability to lead a healthy life. As such, each individual interact with his / her contextual conditions which produce health or ill health.

\section{ACKNOWLEDGEMENT}

Author is sincerely grateful and highly indebted to Dr. Soumendu Chatterjee, the Head, Department of Geography, Presidency University, Kolkata, India.

\section{REFERENCES}

Abler, R., Adams, J. and Gould, P., 1971. Spatial organization: The geographer's view of the world, Prentice Hall, Englewood Cliffs.

Acheson, D., Alleyne, G.A., Casas, J. A., Castillo-Salgado C., Barzach, M., Braveman, P. et al. 2000. Health inequalities and the health of the poor, Bulletin of the World Health Organization, 78(1), pp.75-85.

Akhtar, R. and Izhar, N., 1994. Spatial inequalities and historical evolution in health provision, in D.R. Phillipsand and Y. Verhasselt, (eds): Health and Development, Routledge, London.

Akhtar, R. and Izhar, N., 1986. Inequalities in the distribution of health care in India, in N. Akhtar and A. Learmonth (eds): Geographical aspects of health and disease in India, Concept, New Delhi.

Akhtar, R. and Izhar, N., 1986. The spatial distribution of health resources within countries and communities: examples from India and Zambia, Social Science and Medicine, 22, pp. 1115-1129.

Aronowitz, R.A., 1998. Making Sense of Illness: Science, Society and Disease, Cambridge University Press, Cambridge.

Bailey, T. C. and Gatrell, A. C., 1995. Interactive Spatial Data Analysis, Longman Scientific and Technical, Wiley, New York.

Barry, A.M. and Yuill, C., 2002: Understanding the sociology of health: An introduction, Sage, London.

Bhora, J., Amesur, R. A. and Banerjee, A. C., 1946. Report of the Health Survey and Development Committee, Government of India, New Delhi, Vol.1.

Blackburn, C. 1991. Poverty and Health: Working with Families, Open University Press, Milton Keynes.

Borrell, C and Arias, A. 1995., Socio-economic factors and mortality in urban settings: The case of Barcelona, Spain, Journal of Epidemiology and Community Health, 49, pp. $460-465$.

Carterm C.O. and Peel, J. (eds)., 1976. Equalities and inequalities in Health, Academic Press, London.

Chaurasia, A.R. and Gulati, S.C., 2008. India-the state of population 2007, Oxford University Press, New Delhi.

Coburn, D., 2004. Beyond the income inequality hypothesis: class, neo-liberalis, and health inequalities, Social Science and Medicine, 58, pp. 41-56.

Council for Social Development., 2006. Social Development Report 2006, Oxford University Press, New Delhi.

Deaton, A., 2001. Health, inequality, and development, Commission on Macroeconomics and Health, World Health Organization, Geneva. 
Evans, R. G., Barer, M. L. and Marmor, T.R., 1994. Why are some people healthy and others not? The determinants of health of populations, Aldine de Gruyter, New York.

Frank, J. W. and Mustard, J.F., 1994. The Determinants of Health in a Historical Perspective, Daedalus, 123 (4), pp. 117.

Jejeebhoy, S. J., 1995. Women's education, autonomy and reproductive behaviour: experience from developing countries, Clarendon Press, Oxford.

Meade, M. S. and Earickson, R. J., 2000. Medical Geography, The Guilford Press, New York.

Muntaner, C. and Lynch, J., 1999. Income inequality, social cohesion, and class relations: A critique of Wilknson's neoDurkehimian research program, International Journal of Health Services, 29, pp. 59-81.
Rose, G., 1995. Place and identity: A sense of place, in D. Massey and P. Jess (eds): A Place in the World? Open University Press, Milton Keynes.

Schell, L. M. and Czerwinski, S.A., 1998. Environmental health, social inequality and biological differences, in S.S. Strickland and P.S. Shetty (eds): Human Biology and Social Inequality, Cambridge University Press, Cambridge.

Wade, R. H., 2004. Is globalization reducing poverty and inequality? World Development Report, 32 (4), pp. 567-589.

Wilkinson, R. G., 1996. Unhealthy Societies: The Afflictions of Inequality, Routledge, London.

Wilkinson, R.G. 1997. Socioeconomic determinants of health inequalities: relative or absolute material standards? British medical journal, 314, pp. 591-595.

\section{APPENDIX}

Table 2. Variables considered for Principal Component Analysis

\begin{tabular}{|c|l|c|c|c|c|}
\hline \multirow{2}{*}{ Sl. No } & \multicolumn{4}{|c|}{ Variable } & \multicolumn{3}{c|}{ Component } \\
\cline { 3 - 5 } & & 1 & 2 & 3 & 4 \\
\hline 1 & \% of HH having electricity & .808 & .004 & .030 & .061 \\
\hline 2 & \% of HH with separate kitchen & .697 & .342 & -.122 & -.007 \\
\hline 3 & HH with good environment & .787 & .291 & -.217 & .075 \\
\hline 4 & Average calorie consumption per adult member & .679 & .425 & -.357 & .280 \\
\hline 5 & \% of higher educated male & .525 & .544 & -.295 & .393 \\
\hline 6 & Average income per adult member & .437 & .599 & -.410 & .358 \\
\hline 7 & \% of HH having piped water connection & .440 & .810 & .032 & .163 \\
\hline 8 & \% of HH with safe toilet & .728 & .297 & .003 & -.024 \\
\hline 9 & \%of HH having BPL status & -.638 & -.172 & .168 & -.233 \\
\hline 10 & \% of higher educated female & .465 & .592 & -.264 & .435 \\
\hline 11 & \% of population <15 years of age & -.570 & -.529 & .273 & -.429 \\
\hline 12 & \% of HH having water purification system & .437 & .797 & .034 & .192 \\
\hline 13 & \% of HH with pucca roof & .689 & .255 & .039 & .336 \\
\hline 14 & \% of HH having LPG connection & .674 & .471 & -.204 & .314 \\
\hline 15 & \% of earning member associated with service sector & .488 & .407 & -.417 & .209 \\
\hline 16 & Average family size & .064 & -.059 & .836 & -.216 \\
\hline 17 & Unemployment rate & .131 & -.637 & .389 & .309 \\
\hline 18 & \% of HH with overcrowded & -.450 & -.108 & .588 & .111 \\
\hline 19 & \% of women married in tender age (<18 yrs.) & -.059 & -.097 & .087 & -.774 \\
\hline
\end{tabular}

Table 1. Neighbourhoods with Poor and Poorer categories in Social tier

\begin{tabular}{|c|c|c|c|c|c|}
\hline $\begin{array}{l}\text { Sl. } \\
\text { No }\end{array}$ & $\begin{array}{l}\text { Name of the } \\
\text { neighbourhoods }\end{array}$ & $\begin{array}{l}\text { Index value of Quality of Life } \\
(<-5.00-0.00)\end{array}$ & $\begin{array}{c}\text { Degree of Social } \\
\text { Deprivation }(>60.00) \\
\end{array}$ & $\begin{array}{c}\text { Multiple } \\
\text { Suffering Index }\end{array}$ & Social Class \\
\hline 1 & Iswarpur & $\sqrt{ }$ & $\sqrt{ }$ & $\sqrt{ }$ & Poor \\
\hline 2 & Santinagar & $\sqrt{ }$ & $\sqrt{ }$ & $\sqrt{ }$ & Poorer \\
\hline 3 & Kabardanga & $\sqrt{ }$ & $\sqrt{ }$ & $\sqrt{ }$ & Poorer \\
\hline 4 & Madhyapara & $\sqrt{ }$ & $\sqrt{ }$ & $\sqrt{ }$ & Poorer \\
\hline 5 & Pramodhnagar & $\sqrt{ }$ & $\sqrt{ }$ & $\sqrt{ }$ & Poor \\
\hline 6 & Kastipara & $\sqrt{ }$ & $\sqrt{ }$ & $\sqrt{ }$ & Poorer \\
\hline 7 & Huspukur & $\sqrt{ }$ & $\sqrt{ }$ & $\sqrt{ }$ & Poor \\
\hline 8 & Pradyoutnagar & $\sqrt{ }$ & $\sqrt{ }$ & $\sqrt{ }$ & Poor \\
\hline 9 & Girjabasit & $\sqrt{ }$ & $\sqrt{ }$ & $\sqrt{ }$ & Poorer \\
\hline 10 & Kamarpara & $\sqrt{ }$ & $\sqrt{ }$ & $\sqrt{ }$ & Poor \\
\hline 11 & Mirzamahallah & $\sqrt{ }$ & $\sqrt{ }$ & $\sqrt{ }$ & Poorer \\
\hline 12 & Akarshanagar & $\sqrt{ }$ & $\sqrt{ }$ & $\sqrt{ }$ & Poorer \\
\hline 13 & Ganapatinagar & $\sqrt{ }$ & $\sqrt{ }$ & $\sqrt{ }$ & Poorer \\
\hline 14 & Daspara & $\sqrt{ }$ & $\sqrt{ }$ & $\sqrt{ }$ & Poorer \\
\hline 15 & Manikpur & $\sqrt{ }$ & $\mathrm{v}$ & $\sqrt{ }$ & Poor \\
\hline
\end{tabular}

